Citron, K. M. \& Knox, R. (1954). J. gen. Microbiol. 10, 482-490.

\title{
The Uptake of Thiamine by a strain of Staphylococcus aureus from the Duodenum of a Case of Polyneuritis
}

\author{
By K. M. CITRON AND R. KNOX \\ Department of Bacteriology, Guy's Hospital Medical School, London
}

SUMMARY: A strain of Staphylococcus aureus was isolated from the duodenum of a case of idiopathic steatorrhoea with polyneuritis and evidence of thiamine deficiency. This organism in washed cell suspension in glucose and thiamine at $37^{\circ}$ was found to remove $75 \%$ of the thiamine present within $1 \frac{1}{2} \mathrm{hr}$. This process was much retarded by reduction of the temperature to $4^{\circ}$ and in the absence of glucose. The thiamine which was removed was not destroyed, and death of the organisms resulted in liberation of the thiamine from the organisms into the suspending fluid.

The process may be due to an active transference across cell membranes and concentration of thiamine inside the organism. It is suggested that in the presence of an abnormal intestinal flora such a mechanism may play a part in producing clinical thiamine deficiency states.

Thiamine (vitamin $\mathbf{B}_{1}$, aneurin) is known to be an essential growth factor for certain micro-organisms including staphylococci (Knight, 1937 $a, b$ ). It is also essential to man and its deficiency produces a polyneuritis. There is some evidence to suggest that certain cases of polyneuritis in man are the result of destruction of thiamine in the intestine (Joiner, McArdle \& Thompson, 1950). Such cases may be associated with gastric achlorhydria in which profound changes in the bacterial flora of the intestine have been described (Knott, 1933; Frazer, 1949a), though Cregan, Dunlop \& Haward (1953) have recently thrown doubt on these observations. It has been suggested that changes in the flora of the intestine may play an important part in determining vitamin deficiencies in the host (Frazer, 1949b).

These considerations led us to investigate intestinal organisms from a case of polyneuritis of probable thiamine deficiency origin and to make a study of the behaviour of these organisms with respect to thiamine.

\section{MATERIALS}

The source of micro-organisms used in this investigation was a patient with polyneuritis, a man of 75 years who had for 6 years suffered from looseness of the bowels and a macrocytic anaemia and had recently become bedridden on account of a severe polyneuritis. Investigation revealed steatorrhoea, achlorhydria and macrocytic anaemia; blood pyruvate examination by Prof. R. H. S. Thompson showed evidence of impaired pyruvate metabolism, indicating deranged thiamine metabolism.

A diagnosis of idiopathic steatorrhoea and progressive polyneuritis due to thiamine deficiency was made by $\mathrm{Dr}$ W. N. Mann. The patient's condition deteriorated and he died during a respiratory infection. The findings at autopsy were in keeping with the clinical diagnosis. 
During life gastric contents were obtained from the patient by means of aspiration through a sterile gastric tube. Among the organisms isolated was a strain of Staphylococcus aureus. $10 \mathrm{hr}$. after death fluid was obtained by aseptic aspiration of the duodenum. From this fluid among other organisms Staph. aureus was again isolated.

\section{ME'THODS}

The uptake or destruction of thiamine was studied by making thick washed cell suspensions of the organisms in a solution containing thiamine and glucose and at intervals of time centrifuging the organisms and estimating the thiamine remaining in the supernatant fluid. In preliminary experiments the thiochrome technique was used for estimating thiamine, derived from the methods described by Mawson \& Thompson (1948). A considerable amount of thiamine was found to disappear in the presence of the Staph. aureus suspension.

For quantitative work the microbiological technique of thiamine estimation was used. This method is not subject to the errors resulting from organic substances which may interfere with the thiochrome fluorescence. Washed cell suspensions of the strain of Staph. aureus were made by inoculating a loopful of the organisms from stock culture on blood agar into $5 \mathrm{ml}$. of nutrient broth, incubating for $4 \mathrm{hr}$. and inoculating the whole of this culture on Roux bottles containing nutrient agar and incubating at $37^{\circ}$ for $18 \mathrm{hr}$. The profuse growth obtained was washed off with normal saline and the organisms were washed twice in saline, resuspended in distilled water and the suspensions were standardized turbidimetrically. These suspensions were made up to contain glucose $0.01 \mathrm{M}$, thiamine $4 \mu \mathrm{g} . / \mathrm{ml}$. and Staph. aureus in a concentration of $7.5 \mathrm{mg}$. dry weight per ml. suspension; they were kept at $37^{\circ}$ and sampled at various times as follows. Samples were removed and pipetted into centrifuge tubes standing in iced water. The temperature of the suspension was brought rapidly to $7^{\circ}$. The tubes were centrifuged for $15 \mathrm{~min}$. Some of the clear supernatant fluid was taken, adjusted with acetate buffer to pH 4.8 and thiamine estimations of this solution were made by a plate method of microbiological assay using Lactobacillus fermentum P36, modified from the techniques described by Bacharach \& Cuthbertson (1948), Jones \& Morris (1949), and the operational techniques of Glaxo Laboratories, Middlesex.

Samples were taken at once $\left(0 \mathrm{hr}\right.$.) and after $1 \frac{1}{2} \mathrm{hr}$. incubation at $37^{\circ}$. It will be noted that since the process of separation of the supernatant fluid took about $20 \mathrm{~min}$. this interval of time should be added to the sampling times mentioned.

\section{RESULTS}

\section{Disappearance of thiamine}

In the presence of $0.01 \mathrm{M}$-glucose and this strain of Staph. aureus, there was found to be a considerable disappearance of thiamine. In the $1 \frac{1}{2} \mathrm{hr}$. sample of supernatant fluid the thiamine had fallen to a quarter of the concentration present in the original solution of thiamine. Individual results are shown in Table 1. 
The initial concentration of thiamine in the suspension was $4 \mu \mathrm{g} . / \mathrm{ml}$. as weighed out. In many experiments the accuracy of this figure was checked by microbiological assay.

Table 1. Disappearance of thiamine ( $\mu \mathrm{g} . / \mathrm{ml}$.) in supernatants of suspensions of Staph. aureus in $0.01 \mathrm{M}$-glucose at $37^{\circ}$

\begin{tabular}{|c|c|c|}
\hline $\begin{array}{l}\text { Initial conc. } \\
\text { of thiamine }\end{array}$ & $0 \mathrm{hr}$. & $\mathbf{1}_{\frac{1}{2}} \mathrm{hr}$ \\
\hline 4.0 & $3 \cdot 6$ & $1 \cdot 1$ \\
\hline $4 \cdot 0$ & 3.0 & $1 \cdot 3$ \\
\hline 4.0 & 1.9 & 0.5 \\
\hline $4 \cdot 0$ & 1.7 & 0.5 \\
\hline $4 \cdot 0$ & 1.7 & 0.4 \\
\hline $4 \cdot 0$ & $1 \cdot 6$ & 0.9 \\
\hline $4 \cdot 0$ & $3 \cdot 1$ & 1.5 \\
\hline $4 \cdot 0$ & 3.7 & 1.2 \\
\hline $4 \cdot 0$ & $2 \cdot 7$ & $1 \cdot 4$ \\
\hline 4.0 & 1.7 & 0.8 \\
\hline $4 \cdot 0$ & $\mathbf{2 \cdot 4}$ & 0.7 \\
\hline $4 \cdot 0$ & 1.7 & 0.8 \\
\hline $4 \cdot 0$ & 3.4 & $1 \cdot 1$ \\
\hline $4 \cdot 0$ & $2 \cdot 7$ & 1.2 \\
\hline $4.5 *$ & $3 \cdot 0$ & 1.2 \\
\hline $3 \cdot 8^{*}$ & $2 \cdot 1$ & 0.5 \\
\hline Av. 4.0 & $2 \cdot 5$ & 0.9 \\
\hline
\end{tabular}

* Initial concentrations of thiamine before addition of organisms checked by microbiological assay are marked in the tables with an asterisk.

The average value in twenty-two experiments in which the $4 \mu \mathrm{g}$. thiamine $/ \mathrm{ml}$. as weighed was checked by assay of the solution used was $3 \cdot 8 \mu \mathrm{g} . / \mathrm{ml}$. This average was very near to the expected amount as weighed out. Bacharach $\&$ Cuthbertson (1948) state that the fiducial limits of the method $(P=0.05)$ are $79-133 \%$.

In the presence of the bacterial suspension, the $0 \mathrm{hr}$. values were well below the amount of thiamine actually put in $(4 \mu \mathrm{g} . / \mathrm{ml}$.$) . The average reading in$ sixteen experiments was $2.5 \mu \mathrm{g}$. $/ \mathrm{ml}$. It must be pointed out that whilst these experiments have been labelled ' $0 \mathrm{hr}$.' for convenience, this refers to time of sampling: there was in fact a $20 \mathrm{~min}$. interval between making up the suspensions and the separation of the supernatant fluid from the organisms in the centrifuge, so that disappearance of thiamine must be expected during this period.

At $1 \frac{1}{2} \mathrm{hr}$. the mean value for the thiamine in the supernatant fluid in sixteen experiments was $0.9 \mu \mathrm{g} . / \mathrm{ml}$. This figure was quite outside the range of error of the experimental method and must be interpreted as a real fall in the concentration of the thiamine in the supernatant fluid. The difference between the mean value of the $1 \frac{1}{2} \mathrm{hr}$. readings and the mean value of the initial readings determined experimentally in 18 experiments was highly significant (differentia $=>4 \times$ s.E.D.).

The period over which this disappearance of thiamine occurred was investigated in greater detail. Table 2 shows the results of a typical 
Table 2. Disappearance of thiamine ( $\mu \mathrm{g} . / \mathrm{ml}$.$) in supernatants of suspensions$ of Staph. aureus in $0.01 \mathrm{M}$-glucose at $37^{\circ}$

Initial conen.

of thiamine $\quad 0 \mathrm{hr} . \quad \frac{1}{2} \mathrm{hr} . \quad 1 \mathrm{hr} . \quad 1 \frac{1}{2} \mathrm{hr} . \quad 2 \mathrm{hr} . \quad 2 \frac{1}{2} \mathrm{hr} . \quad 3 \mathrm{hr}$.

$\begin{array}{llllllll}3.8 * & 2.6 & 1.3 & 1.1 & 0.9 & 0.9 & 0.8 & 1 \cdot 1\end{array}$

experiment. It can be seen that the thiamine concentration fell to its lowest level in $1 \frac{1}{2}-2 \frac{1}{2} \mathrm{hr}$. and thereafter increased again. The later increase is better shown in Fig. 1. That this disappearance of thiamine was dependent upon the presence of the strain of staphylococcus in the living state was shown by the following control experiments:

(1) When $0.01 \mathrm{M}$-glucose was incubated with $4 \mu \mathrm{g}$. thiamine $/ \mathrm{ml}$. at $37^{\circ}$ without organisms the thiamine concentration was found to be unchanged (Table 3).

Table 3. Thiamine levels ( $\mu$ g./ml.) in $0.01 \mathrm{M}$-glucose at $37^{\circ}$ in absence of organisms

\begin{tabular}{|c|c|c|c|}
\hline $\begin{array}{l}\text { Initial conen. } \\
\text { of thiamine }\end{array}$ & $0 \mathrm{hr}$. & $1 \frac{1}{2} \mathrm{hr}$. & $24 \mathrm{hr}$ \\
\hline \multirow{6}{*}{4} & & $\begin{array}{l}3 \cdot 4 \\
3 \cdot 1\end{array}$ & $\overline{4.9}$ \\
\hline & $3 \cdot 2$ & $3 \cdot 3$ & $4 \cdot 1$ \\
\hline & $\{4.0$ & 4.0 & $4 \cdot 2$ \\
\hline & 4.0 & $4 \cdot 0$ & $\mathbf{3 . 9}$ \\
\hline & 4.9 & $4 \cdot 5$ & $4 \cdot 3$ \\
\hline & 4.0 & 4.0 & $\mathbf{3 \cdot 9}$ \\
\hline Av. 4 & $3 \cdot 8$ & $3 \cdot 8$ & $4 \cdot 2$ \\
\hline
\end{tabular}

(2) When a suspension consisting of the strain of staphylococcus killed by boiling for $20 \mathrm{~min}$. was incubated with $4 \mu \mathrm{g}$. thiamine $/ \mathrm{ml}$. and $0.01 \mathrm{M}$-glucose at $37^{\circ}$ there was again no significant disappearance of thiamine (Table 4).

Table 4. Thiamine levels ( $\mu \mathrm{g} . / \mathrm{ml}$.) in supernatants of suspensions of boiled Staph. aureus in $0.01 \mathrm{M}$-glucose at $37^{\circ}$

\begin{tabular}{|c|c|c|c|}
\hline $\begin{array}{l}\text { Initial concn. } \\
\text { of thiamine }\end{array}$ & $0 \mathrm{hr}$. & $1 \frac{1}{2} \mathrm{hr}$. & $24 \mathrm{hr}$ \\
\hline $\begin{array}{l}4.0 \\
4.0\end{array}$ & $\begin{array}{l}3 \cdot 3 \\
3 \cdot 7\end{array}$ & $\begin{array}{l}3 \cdot 3 \\
3 \cdot 9 \\
3 \cdot 9\end{array}$ & $3 \cdot 8$ \\
\hline $\begin{array}{l}4.00 \\
4.9^{*}\end{array}$ & $4 \cdot 1$ & $\begin{array}{l}3.9 \\
3 \cdot 2\end{array}$ & \\
\hline $\begin{array}{l}3 \cdot 4^{*} \\
4 \cdot 0\end{array}$ & $\begin{array}{l}3 \cdot 3 \\
3 \cdot 7\end{array}$ & $\begin{array}{l}3 \cdot 4 \\
3 \cdot 3\end{array}$ & $3 \cdot 2$ \\
\hline $4 \cdot 1$ & $3 \cdot 8$ & 3.5 & \\
\hline
\end{tabular}

\section{Effect of temperature}

Experiments performed with the staphylococcus + glucose + thiamine system at $4^{\circ}$ instead of $37^{\circ}$ showed that, apart from an initial fall at $0 \mathrm{hr}$., no subsequent fall in thiamine concentration occurred at $1 \frac{1}{2} \mathrm{hr}$.; see Table 5 . 
Table 5. Thiamine levels ( $\mu$ g. $/ \mathrm{ml}$.) in supernatants of suspensions of Staph. aureus in $0.01 \mathrm{M}$-glucose at $4^{\circ}$

\begin{tabular}{|c|c|c|}
\hline $\begin{array}{c}\text { Initial concn. } \\
\text { of thiamine }\end{array}$ & $0 \mathrm{hr}$. & $1 \frac{1}{2} \mathrm{hr}$. \\
\hline $3 \cdot 8^{*}$ & $3 \cdot 3$ & $3 \cdot 3$ \\
\hline $3 \cdot 4 *$ & $2 \cdot 7$ & $2 \cdot 7$ \\
\hline $3 \cdot 4^{*}$ & $3 \cdot 4$ & $2 \cdot 7$ \\
\hline $4.2 *$ & $2 \cdot 5$ & $3 \cdot 1$ \\
\hline $4 \cdot 3^{*}$ & $\mathbf{2 \cdot 8}$ & $3 \cdot 1$ \\
\hline $4.0 *$ & $2 \cdot 9$ & $3 \cdot 6$ \\
\hline Av. $3 \cdot 9$ & $2 \cdot 9$ & $3 \cdot 1$ \\
\hline
\end{tabular}

\section{Effect of omitting glucose}

Experiments were performed using staphylococci in distilled water and $4 \mu \mathrm{g}$. thiamine $/ \mathrm{ml}$. at $37^{\circ}$ in the absence of glucose. Results are shown in Table 6 and Fig. 1. Although in some experiments the $0 \mathrm{hr}$. readings are considerably below the values given for the initial thiamine concentration, it is clear that the average values show only a slight fall in the thiamine concentration at $0 \mathrm{hr}$. and no further fall at $1 \frac{1}{2} \mathrm{hr}$. or over the subsequent $24 \mathrm{hr}$.

Table 6. Thiamine levels $(\mu \mathrm{g} . / \mathrm{ml}$.) in supernatants of suspensions of Staph. aureus in distilled water at $37^{\circ}$

\begin{tabular}{|c|c|c|}
\hline $\begin{array}{l}\text { Initial concn. } \\
\text { of thiamine }\end{array}$ & $0 \mathrm{hr}$. & $1 \frac{1}{2} \mathrm{hr}$. \\
\hline $4 \cdot 0$ & $2 \cdot 3$ & $2 \cdot 5$ \\
\hline 4.0 & $2 \cdot 5$ & $2 \cdot 5$ \\
\hline $4 \cdot 9 *$ & $3 \cdot 1$ & $\mathbf{3 \cdot 4}$ \\
\hline $5 \cdot 0^{*}$ & $4 \cdot 1$ & $3 \cdot 9$ \\
\hline $3 \cdot 0^{*}$ & $\mathbf{3} \cdot \mathbf{3}$ & $2 \cdot 4$ \\
\hline $3 \cdot 0 *$ & $2 \cdot 5$ & $3 \cdot 0$ \\
\hline $3 \cdot 0 *$ & $2 \cdot 7$ & $2 \cdot 5$ \\
\hline $3.9 *$ & $3 \cdot 9$ & $4 \cdot 2$ \\
\hline $3 \cdot 9 *$ & $4 \cdot 0$ & $4 \cdot 2$ \\
\hline $4 \cdot 0^{*}$ & $3 \cdot 9$ & $3 \cdot 4$ \\
\hline Av. 3.9 & $2 \cdot 3$ & $3 \cdot 2$ \\
\hline
\end{tabular}

Effect of continued incubation

Estimations of the thiamine in the supernatant from the thiamine + glucose + staphylococcus suspension at $37^{\circ}$ over periods of 24-48 hr. were made (Table 7 ). Results of frequent estimations made over $24 \mathrm{hr}$. are shown in Fig. 1. The results of control experiments using boiled staphylococci and live staphylo-

Table 7. Thiamine levels ( $\mu \mathrm{g} . / \mathrm{ml}$.) in supernatants of suspensions of Staph. aureus in 0.01 M-glucose at $37^{\circ}$ over $48 \mathrm{hr}$.

\begin{tabular}{|c|c|c|c|c|}
\hline $\begin{array}{l}\text { Initial concn. } \\
\text { of thiamine }\end{array}$ & $\mathrm{o} \mathrm{hr}$. & $1 \frac{1}{2} \mathrm{hr}$. & $24 \mathrm{hr}$. & $48 \mathrm{hr}$. \\
\hline \multirow{3}{*}{4} & $1 \cdot 7$ & 0.5 & 2 & $2 \cdot 1$ \\
\hline & $1 \cdot 7$ & 0.8 & $2 \cdot 4$ & $3 \cdot 6$ \\
\hline & 1.7 & $0 \cdot 6$ & $2 \cdot 8$ & 2.7 \\
\hline
\end{tabular}


cocci in distilled water are also shown. Viable counts upon the glucose and distilled water suspensions are also given.

From these it will be noted that after the initial fall in thiamine levels in the first $1 \frac{1}{2} \mathrm{hr}$. there was a gradual rise to a steady level after $20 \mathrm{hr}$. and thereafter the level remained constant. Thus, after falling to a value of $0.6 \mu \mathrm{g} . / \mathrm{ml}$. at $1 \frac{1}{2} \mathrm{hr}$. there was a rise to $2.9 \mu \mathrm{g}$. $/ \mathrm{ml}$. at 20 and $24 \mathrm{hr}$. (Fig. 1). No such rise in the thiamine occurred with the staphylococci suspended in distilled water.

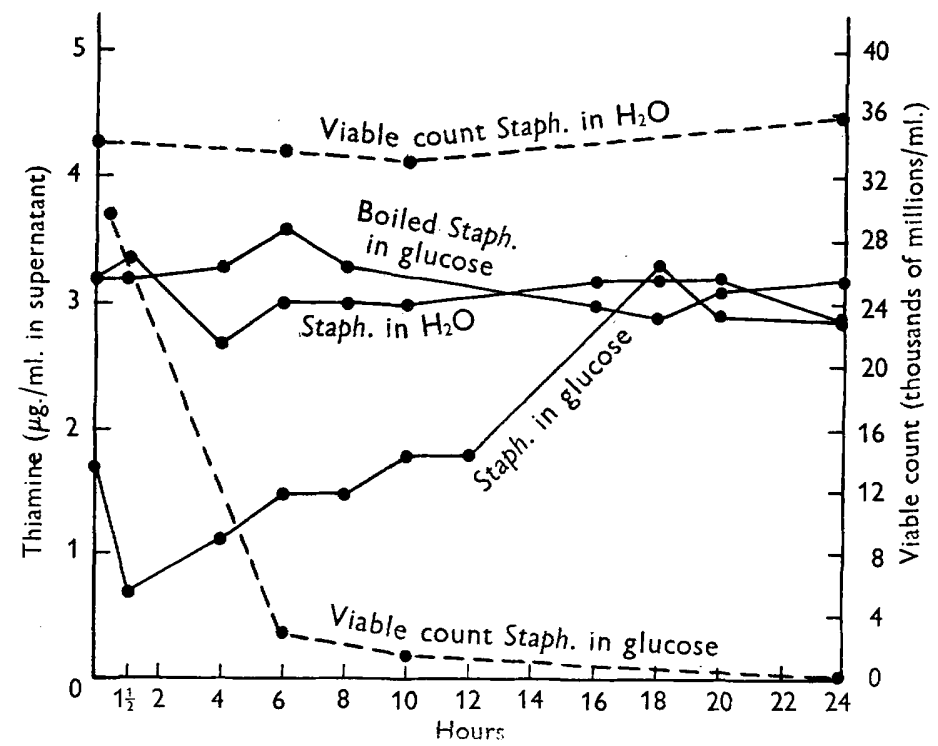

Fig. 1. Relation between viable counts and concentrations of thiamine ( $\mu \mathrm{g} . / \mathrm{ml}$.$) in super-$ natants of suspensions of Staph. aureus in $0.01 \mathrm{M}$-glucose and in distilled water over $24 \mathrm{hr}$. Control of boiled Staph. aureus in $0.01 \mathrm{M}$-glucose containing no viable organisms.

Viable counts showed that in glucose at $37^{\circ}$ there was a rapid fall in the number of viable organisms: the number at $6 \mathrm{hr}$. was only one-sixth of that at $1 \mathrm{hr}$. This is in contrast to the comparatively constant viable count over $24 \mathrm{hr}$. in water at $37^{\circ}$. In other experiments using the glucose + staphylococcus system at $4^{\circ}$ the viable counts were also found to be constant. The fall in viable counts in glucose at $37^{\circ}$ was associated with a fall in the $\mathrm{pH}$ value of the suspension from 6.8 at $0 \mathrm{hr}$. to 4.4 at $4 \mathrm{hr}$. Thereafter the $\mathrm{pH}$ value remained constant at $\mathbf{4 \cdot 4}$.

\section{Effect of boiling}

The viable counts suggested that death of the organisms might be associated with a reappearance of thiamine. Experiments in which the organisms in the staphylococcus + thiamine + glucose suspension were killed by boiling were therefore performed.

In one experiment the thiamine in the supernatant fluid was estimated at 0 and $1 \frac{1}{2} \mathrm{hr}$. and a sample of the $1 \frac{1}{2} \mathrm{hr}$. suspension was boiled for $20 \mathrm{~min}$., 
centrifuged and the supernatant fluid assayed for thiamine. Results are shown in Table 8.

Table 8. Table showing return of thiamine ( $\mu \mathrm{g} . / \mathrm{ml}$.) to supernatant following boiling of suspensions of live Staph. aureus in $0.01 \mathrm{M}$-glucose at $37^{\circ}$ after $1 \frac{1}{2} h r$.

\begin{tabular}{|c|c|c|}
\hline & $\begin{array}{c}\text { Live } \\
\text { organisms }\end{array}$ & $\begin{array}{c}\text { Boiled } \\
\text { organisms }\end{array}$ \\
\hline $0 \mathrm{hr}$. & $3 \cdot 4$ & 4.5 \\
\hline $1 \frac{1}{2} \mathrm{hr}$. & $0 \cdot 1$ & $3 \cdot 9$ \\
\hline $\begin{array}{l}\mathrm{I}_{2}^{\frac{1}{2}} \mathrm{hr} \text { suspension boiled } \\
\text { for } 20 \mathrm{~min} \text {. }\end{array}$ & $4 \cdot 8$ & $3 \cdot 8$ \\
\hline
\end{tabular}

Initial thiamine concn. $=4 \mu \mathrm{g} . / \mathrm{ml}$.

It is seen that boiling resulted in a return of thiamine in the supernatant fluid to approximately its initial value of $4 \mu \mathrm{g} . / \mathrm{ml}$.

\section{Effect of Cetrimide}

Similar results were obtained using Cetrimide in place of boiling. In these experiments the microbiological assay could not be used, for the Cetrimide would interfere with the growth of the test organism so that the thiochrome method had to be used. These experiments showed that much of the thiamine which had been removed from the $1 \frac{1}{2} \mathrm{hr}$. sample could be recovered by adding $\mathbf{0 . 2 5} \%$ Cetrimide to the $1 \frac{1}{2} \mathrm{hr}$. suspension and separating the supernatant fluid, which showed about as much thiamine as in the control solution.

\section{Experiments with other organisms}

A few experiments were performed with strains of Oxford staphylococcus, Escherichia coli, and Proteus vulgaris. These indicated that, whilst the property of thiamine removal is probably not confined to the strain of Staph. aureus isolated in the present work, it is very much less well marked in these other organisms.

\section{DISCUSSION}

These observations show that in the presence of the staphylococcus and glucose at $37^{\circ}$ there was a considerable fall in the concentration of thiamine in the solution after $1 \frac{1}{2} \mathrm{hr}$. This did not take place in the absence of organisms or in the presence of organisms previously killed by boiling. The process is therefore dependent upon the presence of living organisms. The fall in the concentration of thiamine is the result of removal of thiamine by the organism rather than its destruction, for on continued incubation over $24 \mathrm{hr}$. much of the thiamine reappears. The thiamine is in some way taken up by the living organisms and subsequently released. Study of the relation between this liberation of thiamine and fall in the viable count (Fig. 1) and experiments in which organisms were killed by boiling or the action of Cetrimide suggest that whilst living organisms are essential for the removal of thiamine its subsequent liberation is related to the death of the organism. 
The fall in $\mathrm{pH}$ value which occurs during the incubation of the staphylococcus + glucose + thiamine system was not thought to be a primary factor in the change in thiamine concentration for whilst the $\mathrm{pH}$ fell to its lowest value in $4 \mathrm{hr}$. there was, during this time, an initial fall and subsequent rise in thiamine concentration, and this rise continued over the next $18 \mathrm{hr}$. in the presence of a persistent low $\mathrm{pH}$. Detailed investigation of the effect of $\mathrm{pH}$ was rendered difficult by the fact that the addition of acetate or phosphate buffers irrespective of their $\mathrm{pH}$ produced an effect rather like that of Cetrimide in releasing thiamine from the organisms.

In the absence of glucose there was less removal of thiamine by the organisms in the $0 \mathrm{hr}$. sample than in the presence of glucose (a removal of only $0.7 \mu \mathrm{g} . / \mathrm{ml}$. as compared with that of $1.5 \mu \mathrm{g} . / \mathrm{ml}$.) and in the absence of glucose no further removal of thiamine occurred on continued incubation. This indicates that glucose is necessary for continued removal of thiamine after the time of separation of the $0 \mathrm{hr}$. sample (about $20 \mathrm{~min}$. after making up the suspension), and that it accelerates the removal of thiamine before this time. It is possible therefore that the initial removal of thiamine reflected in the low $0 \mathrm{hr}$. values may in part be due to a mechanism different from that responsible for the later removal of thiamine.

When the temperature of the glucose suspension was reduced to $4^{\circ}$ the activity was much curtailed.

The behaviour of the process in respect to glucose and temperature suggests that there is an active removal of thiamine from the surrounding fluid by the organisms in a viable state. Such a process resembles in many features that demonstrated by Gale (1947) for glutamic acid. He showed that glutamic acid is removed from the external environment and concentrated inside Streptococcus faecalis in washed cell suspension in the presence of fermentable glucose by an active process of transference through the cell membrane. The process was reversed by damaging the cell membrane by boiling or by Cetrimide. However, whatever may be the explanation, the uptake of thiamine under the conditions described here does appear to be an established fact.

Destruction of thiamine by yeasts in vitro has been demonstrated (Lewis, 1944) and there is evidence that such a process may occur in the intestine when live yeast is fed to man by mouth (Williamson \& Parsons, 1945). Ellinger \& Benesch (1945) showed in vitro that mixed organisms from the colon of man can destroy nicotinic acid. Our experiments have revealed another phenomenon in which a vitamin is removed from the environment and stored rather than destroyed by the living organism. This property may be of biological significance to the organism, for if an organism is thiamine dependent and most strains of staphylococcus are (Knight, 1937a, b), then it is clearly of value if the organism is able to take up thiamine, thus securing a ready supply of the vitamin for use should it be faced with circumstances in which a suboptimal concentration of the vitamin occurs.

Could the presence of this organism have played a part in determining thiamine deficiency in the host? We have no direct proof, but it may be 
observed that if there were a heavy infection with this organism and the phenomenon of thiamine uptake were to occur in the intestine it is not unreasonable to suppose that the thiamine in the diet (normally a few milligrams per day) might be taken up by the organism, and since in the faeces there is a considerable weight of living organisms, the thiamine thus captured might entirely escape absorption by the host.

We should like to thank Prof. R. H. S. Thompson for stimulating our interest in the problem and for his help throughout the investigation, and Dr W. F. J. Cuthbertson, Glaxo Laboratories, for his ready advice on the techniques and problems of thiamine assay. We are also grateful to Dr W. N. Mann for making it possible for us to investigate his patient.

\section{REFERENCES}

Bacharach, A. L. \& Cuthbertson, W. F. J. (1948). The cup plate method in microbiological assay with special reference to riboflavine and aneurine. Analyst, 73, 334.

Cregan, J., Dunlop, E. E. \& Haward, N. J. (1953). The bacterial content of the human small intestine in diseases of the stomach. Brit. med. J. ii, 1248.

Ellinger, P. \& Benesch, R. (1945). Biosynthesis of 'Nicotinamide' in the human gut. Lancet, i, 482.

Frazer, A. C. (1949a). A new mechanism of vitamin deprivation. Brit. med. J. ii, 731.

Frazer, A. C. $(1949 b)$. Fat metabolism and the sprue syndrome. Brit. med. J. ii, 769.

GaLe, E. F. (1947). The assimilation of amino acids by bacteria. J. gen. Microbiol. 1, 53.

Jorner, C. L., McArdle, B. \& Thompson, R. H. S. (1950). Blood pyruvate estimations in the diagnosis and treatment of polyneuritis. Brain, 73, 431.

Jones, A. \& Monris, S. (1949). The use of the plate method for the assay of aneurine in yeast and yeast products. Analyst, 74, 333 .

KNIGHT, B. C. J. G. (1937a). The nutrition of Staphylococcus aureus; nicotinic acid and vitamin $\mathrm{B}_{1}$. Biochem. J. 31, 731 .

KNight, B. C. J. G. $(1937 b)$. The nutrition of Staphylococcus aureus. The activities of nicotinamide, aneurin (vitamin $\mathrm{B}_{1}$ ) and related compounds. Biochem. J. 31, 966.

KNotr, F. A. (1933). Duodenal intubation in gall-bladder disease. Guy's Hosp. Rep. 83, 347.

LEwrs, J. C. (1944). The relationship of iron nutrition to synthesis of vitamins by Torulopsis utilis. Arch. Biochem. 4, 217.

Mawson, E. H. \& Thompson, S. Y. (1948). A note on the estimation of vitamin $B_{1}$ in urine. Biochem. J. 43, 2.

Williamson, A. \& Parsons, H. T. (1945). Some factors influencing faecal elimination of thiamine by human subjects. J. Nutr. $29,51$. 